\title{
Clubes de Programação com Scratch nas Escolas e a Interdisciplinaridade
}

\author{
Eliana S. Lisbôa ${ }^{1}$, Helio H. L. C. Monte-Alto ${ }^{1}$, Maria L. da Silva ${ }^{1}$ \\ ${ }^{1}$ Universidade Federal do Paraná (UFPR) - Setor Palotina - Palotina, PR - Brazil \\ \{eliana.lisboa, heliohenrique, luizasilva\}@ufpr.br
}

\begin{abstract}
This work is the result of a study with elementary school students who attended the Code Club conducted in Palotina-PR, whose main goal is to contribute to the development of the logical reasoning and computational thinking of the students in an interdisciplinary way. This study, in what concerns interdisplinarity, incited on three distinct disciplines: Math, History and Geography. One of the performed activities, in the context of History and Geography, focused mainly in providing the students with a reflection on the history of Brazil's discovery. As a result, students developed a game by means of the Scratch programming environment which simulated the discoveries. In this game, additionally to the History and Geography contents, it was also needed the application of Math concepts which are essential to game and animation development. Given this study, it can be observed that the Scratch environment is a tool with great educational potential in Basic Education, enabling the creation of programs involving various areas of knowledge in an interdisciplinary and contextualized way.
\end{abstract}

Resumo. Este trabalho é o resultado de um estudo com alunos do ensino fundamental participantes do clube de programação realizado na cidade de Palotina$P R$, cujo objetivo principal é contribuir para o desenvolvimento do raciocínio lógico e do pensamento computacional dos discentes de forma interdisciplinar. $O$ referido estudo, no âmbito interdisciplinar, incidiu sobre três disciplinas distintas: Matemática, História e Geografia. Uma das atividades desenvolvidas, no contexto de História e Geografia, teve como foco principal propiciar aos alunos uma reflexão crítica acerca da história do descobrimento do Brasil. Para o feito, os alunos desenvolveram um jogo no ambiente de programação Scratch que simulava o descobrimento do Brasil. Nesse jogo, além dos conteúdos de História e Geografia, foram necessários também conhecimentos de Matemática, essenciais para o desenvolvimento de jogos e animações no Scratch. Tendo como base o estudo realizado, observa-se que o ambiente Scratch é uma ferramenta com grande potencial educativo na Educação Básica que permite a criação de programas envolvendo várias áreas do saber de forma interdisciplinar e contextualizada.

\section{Introdução}

No contexto atual, a Computação integra praticamente todos os segmentos sociais. Os computadores são utilizados nas diversas atividades humanas e hoje é praticamente impossível pensarmos nossa sociedade sem esse recurso. Segundo [França et al. 2014], 
"Em qualquer atividade profissional, haverá pelo menos o uso de tecnologias da informação atrelada a um raciocínio computacional (algorítmico). Ainda, existem inúmeros problemas das áreas das Ciências Exatas, Humanas, Artes, e da realidade cotidiana que poderiam ser resolvidos com o seu auxílio."

Dessa forma, é de fundamental importância que profissionais das variadas áreas de conhecimento trabalhem de forma interdisciplinar com o profissional da área de informática, mais especificamente o licenciado em computação, para que, juntos, possam pensar ações que visem o desenvolvimento do aluno, pois é conhecido que programar ajuda a desenvolver o raciocínio lógico, o pensamento computacional, reforça o pensamento matemático e a capacidade de resolução de problemas, competência essa primordial para o cidadão do século XXI [Grandell et al. 2006, Wing 2006].

Partindo desse pressuposto vem sendo desenvolvido um projeto que tem como finalidade proporcionar aos estudantes do Ensino Fundamental de Palotina-PR e região a oportunidade de aprender conceitos básicos de programação de computadores como uma forma de complemento ao ensino de Matemática e Informática de forma interdisciplinar por meio da ferramenta Scratch. O formato utilizado nas aulas é baseado no Code Club ("clube de programação"), uma rede mundial de voluntariado para o ensino de programação para crianças.

O objetivo deste trabalho é apresentar um estudo realizado com os alunos participantes desse clube de programação, no qual é trabalhado em grande parte projetos que requerem o uso de conceitos matemáticos, e, em um dos projetos, trabalha-se com alguns conceitos das disciplinas de História e Geografia, tendo a tecnologia (Scratch) como uma ferramenta facilitadora do processo de ensino e aprendizagem.

\section{Materiais e Métodos}

O ponto de partida para realização do projeto foi a análise e estudos sobre abordagens e planos de ensino utilizando a linguagem de programação Scratch. O ambiente Scratch é resultado de intensa pesquisa, nos últimos anos, na área de ensino de programação [Maloney et al. 2010].

O estudo envolveu alunos do Ensino Fundamental de uma escola de PalotinaPR que, no contra-turno, reúnem-se com os alunos bolsistas e voluntários do curso de graduação em Licenciatura em Computação sob a supervisão do coordenador, vicecoordenador do projeto e colaboradores. No primeiro momento, é-lhes apresentada a ferramenta Scratch e são desenvolvidas atividades de desenvolvimento de jogos eletrônicos e animações utilizando essa ferramenta. Essas atividades são divididas em módulos baseados no material fornecido pela Code Club Brasil $^{1}$, e têm como finalidade desenvolver o pensamento lógico e computacional dos alunos.

No entanto, dentre essas atividades, percebeu-se que vários conceitos matemáticos necessitam ser compreendidos para desenvolver os jogos e animações, surgindo então a ideia de desenvolver atividades de forma contextualizada e interdisciplinar, como forma de ajudá-los na aprendizagem de temas abordados em sala de aula.

\footnotetext{
${ }^{1}$ Para mais informações sobre a Code Club Brasil, visite: http://www. codeclubbrasil.org. br
} 
De fato, a Ciência da Computação é, em grande parte, baseada na Matemática. Portanto, é natural que, ao aprender essa disciplina, seja necessário envolver conceitos matemáticos. O desenvolvimento de jogos e animações acentuam ainda mais essa relação entre ambas as disciplinas, uma vez que é necessário utilizar diversos conceitos matemáticos, tais como o plano cartesiano, o Teorema de Pitágoras, e noções de ângulos, variáveis e aleatoriedade.

Um exemplo interessante desenvolvido nos encontros do Code Club é uma animação em que um foguete deve chegar ao planeta Terra. Ambos são posicionados no cenário e, consequentemente, cada um tem sua posição $x$ e $y$ no espaço. Um dos objetivos do projeto é fazer com que o foguete se desloque até a mesma posição em que está a Terra. Para isso, é necessário que haja o entendimento do plano cartesiano, pois é necessário conhecer a posição no eixo $x$ e no eixo $y$ para criar o comando que faz o foguete realizar esse movimento. A Figura 1 ilustra um quadro dessa animação e como se introduz o plano cartesiano ao mudar o pano de fundo do cenário para um que torna $o$ plano explícito.

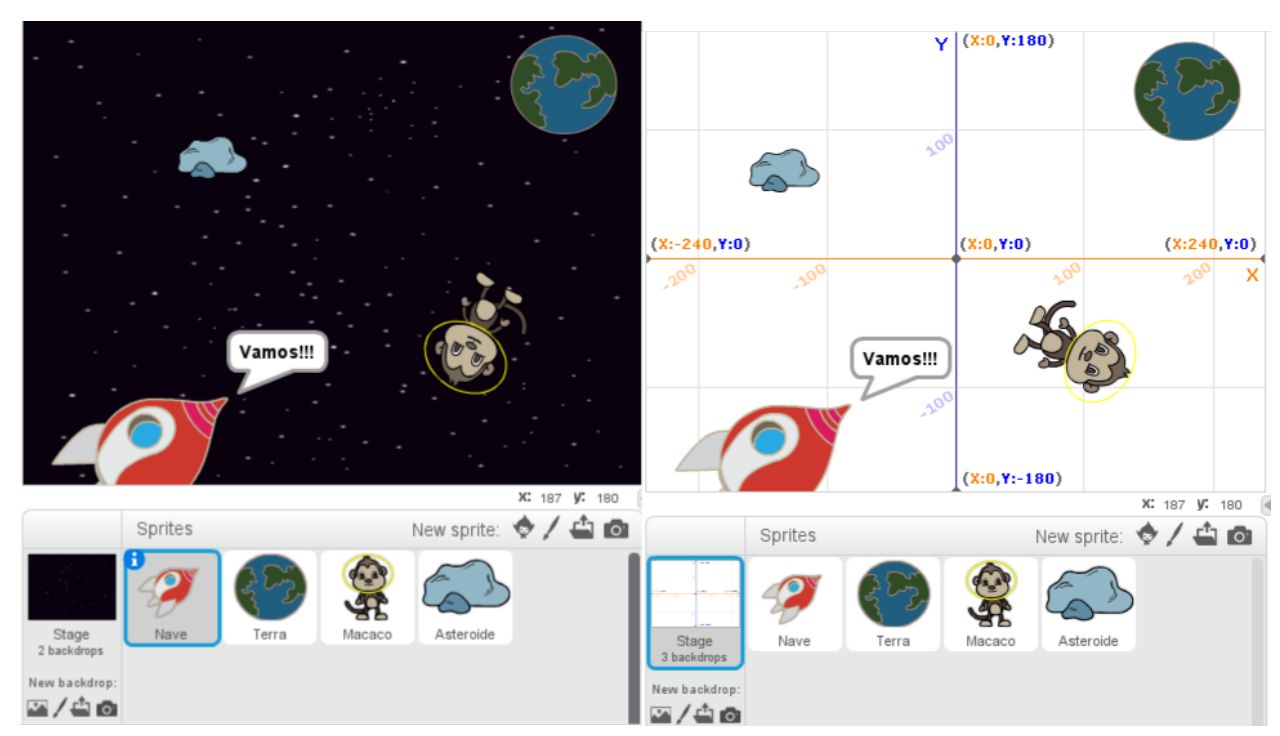

Figura 1. Imagens da animação "Perdidos no Espaço" desenvolvida pelos próprios alunos e como é introduzido o plano cartesiano.

Além disso, foi considerada a possibilidade de envolver outras disciplinas além da Matemática em algumas atividades. Sendo assim, foi tomado como ponto de partida um conteúdo curricular e, a partir daí, em discussão com os alunos, foram evidenciadas algumas questões interessantes de serem trabalhadas, visando a aprendizagem de conteúdos ministrados em sala de aula. No caso específico do presente estudo, foram envolvidas áreas de conhecimento da História e Geografia, com a temática "Descobrimento do Brasil".

No primeiro momento, foi pedido que cada aluno pesquisasse em diferentes fontes (tais como livros e sites da Internet) informações sobre o tema. Em seguida, foi estudada a rota do descobrimento do Brasil (por meio de mapas) com a finalidade de suscitar nos alunos a reflexão se, de fato, o descobrimento do Brasil ocorreu por um equívoco de navegação ou por uma ação intencional. Após sucessivas discussões, foi proposto que os 
alunos desenvolvessem um jogo eletrônico que simulasse o trajeto percorrido por Cabral desde Lisboa até às Índias, passando pelo Brasil.

Por meio do ambiente de programação do Scratch, os alunos construíram o cenário do jogo como o próprio mapa-múndi, desenharam a embarcação dos descobridores e então programaram a lógica do jogo, no qual deve-se direcionar, por meio do mouse ou do teclado do computador, a embarcação para que chegue primeiramente ao Brasil e depois rume à Índia. Foram inseridos, ainda, elementos de desafio no cenário do jogo, constituídos pela própria geografia desenvolvida pelos alunos. Por exemplo, ao tentar embarcar em uma costa diferente da do Brasil ou da Índia, a embarcação se quebra, perdendo-se pontos. Os alunos foram estimulados, ainda, a soltarem a imaginação inserindo novos elementos no mapa, tais como tubarões e monstros marinhos. Tudo isto tornou a atividade muito lúdica e divertida, exercitando os conhecimentos relacionados às disciplinas de História e Geografia. Implicitamente, a atividade também exercitou conceitos matemáticos tais como o plano cartesiano, uma vez que a correta disposição dos elementos do jogo depende de se conhecer e manipular suas posições nos eixos $x$ e $y$. Algumas fotos dos jogos desenvolvidos pelos alunos são apresentadas na Figura 2.
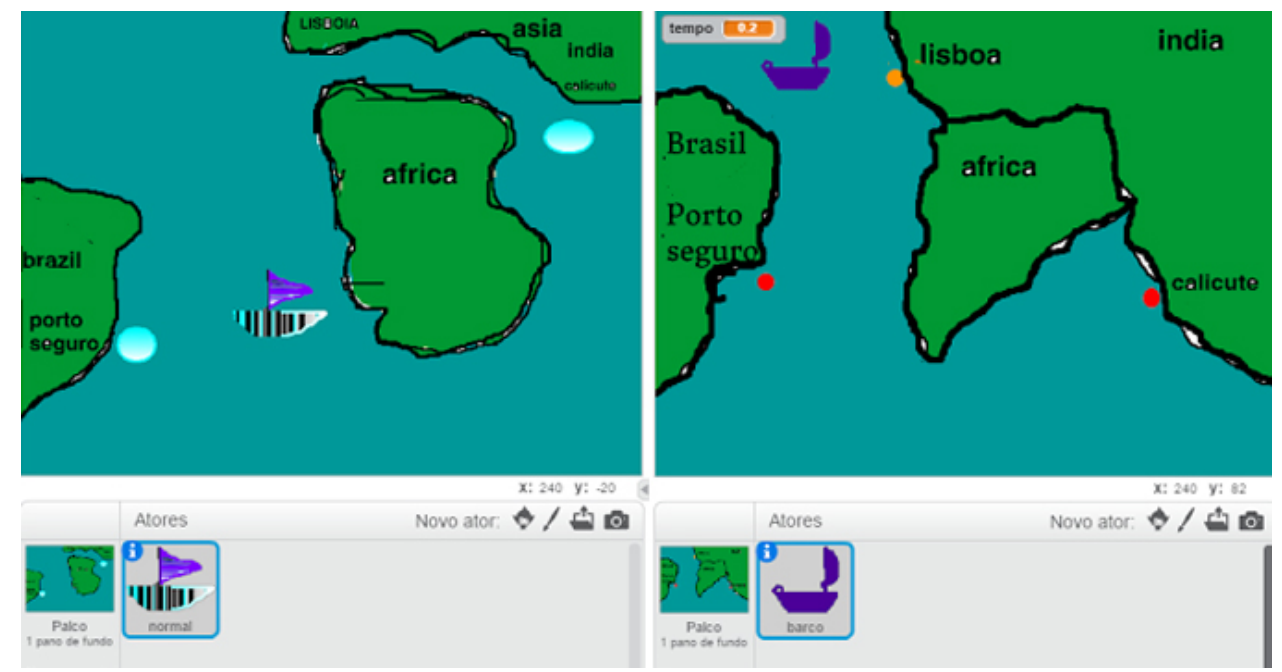

Figura 2. Fotos dos jogos com temática de descobrimento do Brasil desenvolvidos pelos alunos.

\section{Resultados e Discussão}

Um questionário foi aplicado aos alunos que foram até o final do módulo do curso, no qual, de 27 alunos que responderam, 15 são do sexo feminino e cursam do $6^{\circ}$ ao $9^{\circ}$ ano. 24 alunos responderam que gostaram de trabalhar com a ferramenta Scratch, e que ficou mais fácil entender a Matemática e outros conteúdos por meio da programação de computadores. Isto demonstra que, de fato, existe um impacto na aprendizagem dessa disciplina por meio da programação com Scratch.

A pergunta seguinte tinha a ver com a atividade desenvolvida (descobrimento do Brasil e a animação do foguete). Todos foram unânimes em responder que com o Scratch foi possível vivenciar, na prática (ações concretas), alguns conteúdos que muitas das vezes são abordados em sala de aula de forma abstrata, impedindo-os de compreenderem e desenvolverem um entendimento assertivo sobre o assunto estudado. 
VI Congresso Brasileiro de Informática na Educação (CBIE 2017)

Anais do XXIII Workshop de Informática na Escola (WIE 2017)

Também foi questionado se a aprendizagem por meio lúdico os deixaram mais motivados. Com relação a esta questão, novamente os alunos foram unânimes em responder que estudar assim torna a aula mais interessante, porque em vez de ficarem somente escutando o professor falar, eles se envolvem mais e isso torna a aula mais motivadora. Essa resposta vem a demonstrar que quando o aluno é colocado como centro do processo, assumindo o seu protagonismo, além de desenvolver a autonomia, propicia uma aprendizagem significativa, uma vez que, teoricamente, envolve três tipos de conhecimento: o declarativo, o procedimental e o estrutural [Jonassen 2007].

O pensamento declarativo tem a ver com a definição de ideias, ou o conhecimento que temos sobre algo. O conhecimento procedimental diz respeito a saber como usar o conhecimento declarativo na resolução de um problema e, por fim, o conhecimento estrutural é a capacidade de integrar e estabelecer inter-relações entre as ideias dentro de uma determinada temática, que no caso específico do estudo envolveu conceitos de Matemática, História e Geografia. Além disso, a programação de um jogo eletrônico contribui para com o desenvolvimento do pensamento lógico e computacional dos alunos.

\section{Considerações Finais}

Tornou-se evidente, deste modo, pelo feedback dos participantes, o quanto a atividade de programação com Scratch é lúdica e interessante para a faixa etária. O despertar do interesse dos alunos pela programação de computadores é algo necessário no mundo em constante crescimento tecnológico, além de incentivar o pensamento matemático e lógico e a habilidade de resolução de problemas, necessária em todas as áreas de conhecimento.

Este estudo vem a corroborar com os estudos de [Jonassen 2007], quando enfatiza que as ferramentas informáticas devem ser usadas como parceiras intelectuais dos alunos, ou seja, como meio propulsor de desenvolvimento dos processos psicológicos superiores (análise, reflexão, criatividade, etc.). No caso específico do estudo, foi interessante os alunos questionarem e entenderem, na prática, um acontecimento histórico que muitas das vezes é desenvolvido em sala de aula sem uma análise mais profícua dos fatos e das intencionalidades que o compõem.

\section{Referências}

França, R., Ferreira, V., Almeida, L. d., and Amaral, H. d. (2014). A disseminação do pensamento computacional na educação básica: lições aprendidas com experiências de licenciandos em computação. In Anais do XXII Workshop sobre Educação em Computação (WEI-CSBC).

Grandell, L., Peltomäki, M., Back, R. J., and Salakoski, T. (2006). Why complicate things? Introducing programming in high school using Python. Conferences in Research and Practice in Information Technology Series, 52:71-80.

Jonassen, D. H. (2007). Computadores, ferramentas cognitivas-desenvolver o pensamento crítico nas escolas. Porto: Porto Editora.

Maloney, J., Resnick, M., Rusk, N., Silverman, B., and Eastmond, E. (2010). The scratch programming language and environment. Trans. Comput. Educ., 10(4):16:1-16:15.

Wing, J. M. (2006). Computational thinking. Communications of the ACM, 49(3):33-35. 